\title{
Correction to: Electropulsing Treatment on Enhancement of Electrical Conductivity of Screen-Printed Ag Wire
}

\author{
Ju-Won Park ${ }^{1} \cdot$ Howook Choi ${ }^{1} \cdot$ Hwangsun $\mathrm{Kim}^{1}$ · Simoon Sung ${ }^{1} \cdot$ Hye-Jin Jeong ${ }^{1} \cdot$ II Kim $^{2}$. Jaeseok Gong ${ }^{2}$. \\ Sung-Tae Hong ${ }^{3} \cdot$ Heung Nam Han ${ }^{1}$
}

Published online: 30 April 2020

(c) The Korean Institute of Metals and Materials 2020

\section{Correction to: Metals and Materials international https://doi.org/10.1007/s12540-019-00555-1}

The original version of this article, unfortunately, contained a mistake. The acknowledgements section was incomplete. The correct information is given below.

Acknowledgements This work was supported by the National Research Foundation of Korea (NRF) grant funded by the Korea Government (MSIT) (No. NRF- 2015R1A5A1037627). The Institute of Engineering Research at Seoul National University provided research facilities for this work. Also, this work was supported by Manufacturing Core
Technology Team in Global Technology Center of Samsung Electronics Co., Ltd. SS was supported by a Korea Institute for Advancement of Technology grant, funded by the Korea Government (MOTIE) (P0002019), as part of the Competency Development Program for Industry Specialists. HC was supported by POSCO Science Fellowship of POSCO TJ Park Foundation.

Publisher's Note Springer Nature remains neutral with regard to jurisdictional claims in published maps and institutional affiliations.

The original article can be found online at https://doi.org/10.1007/ s12540-019-00555-1.

Heung Nam Han

hnhan@snu.ac.kr

1 Department of Materials Science and Engineering and Research Institute of Advanced Materials, Seoul National University, Seoul 08826, Republic of Korea

2 Hardware Engineering Group, Samsung Electronics, Suwon 16677, Republic of Korea

3 School of Mechanical Engineering, University of Ulsan, Ulsan 44610, Republic of Korea 